\title{
BMJ Open Sex differences in vectorcardiogram of African-Americans with and without cardiovascular disease: a cross-sectional study in the Jackson Heart Study cohort
}

\author{
James D Pollard, ${ }^{1}$ Kazi T Haq, ${ }^{2}$ Katherine J Lutz, ${ }^{2}$ Nichole M Rogovoy, ${ }^{2}$ \\ Kevin A Paternostro, ${ }^{2}$ Elsayed Z Soliman, ${ }^{3}$ Joseph Maher, ${ }^{1}$ Joao AC Lima, ${ }^{4}$ \\ Solomon Musani, ${ }^{1}$ Larisa G Tereshchenko (i) ${ }^{2,4}$
}

To cite: Pollard JD, Haq KT, Lutz KJ, et al. Sex differences in vectorcardiogram of AfricanAmericans with and without cardiovascular disease: a crosssectional study in the Jackson Heart Study cohort. BMJ Open 2021;11:e042899. doi:10.1136/ bmjopen-2020-042899

- Prepublication history and additional material for this paper are available online. To view these files, please visit the journal online (http://dx.doi. org $/ 10.1136 /$ bmjopen-2020042899).

JDP and KTH contributed equally.

Received 18 July 2020

Revised 19 December 2020 Accepted 11 January 2021

Check for updates

(c) Author(s) (or their employer(s)) 2021. Re-use permitted under CC BY-NC. No commercial re-use. See rights and permissions. Published by BMJ.

For numbered affiliations see end of article.

Correspondence to Dr Larisa G Tereshchenko; tereshch@ohsu.edu

\section{ABSTRACT}

Objectives We hypothesised that (1) the prevalent cardiovascular disease (CVD) is associated with global electrical heterogeneity (GEH) after adjustment for demographic, anthropometric, socioeconomic and traditional cardiovascular risk factors, (2) there are sex differences in GEH and (3) sex modifies an association of prevalent CVD with GEH.

Design Cross-sectional, cohort study.

Setting Prospective African-American The Jackson Heart Study (JHS) with a nested family cohort in 2000-2004 enrolled residents of the Jackson, Mississippi metropolitan area.

Participants Participants from the JHS with analysable ECGs recorded in 2009-2013 ( $n=3679 ; 62 \pm 12 y ; 36 \%$ men; 863 family units). QRS, $T$ and spatial ventricular gradient (SVG) vectors' magnitude and direction, spatial QRS-T angle and sum absolute QRST integral (SAI QRST) were measured.

Outcome Prevalent CVD was defined as the history of (1) coronary heart disease defined as diagnosed/ silent myocardial infarction, or (2) revascularisation procedure defined as prior coronary/peripheral arterial revascularisation, or (3) carotid angioplasty/carotid endarterectomy, or (4) stroke.

Results In adjusted mixed linear models, women had a smaller spatial QRS-T angle $(-12.2(95 \% \mathrm{Cl}-19.4$ to -5.1$\left.)^{\circ} ; p=0.001\right)$ and SAl QRST $(-29.8(-39.3$ to $\left.-20.3) \mathrm{mV}^{*} \mathrm{~ms} ; p<0.0001\right)$ than men, but larger SVG azimuth $\left(+16.2(10.5-21.9)^{\circ} ; \mathrm{p}<0.0001\right)$, with a significant random effect between families $\left(+20.8(8.2-33.5)^{\circ}\right.$; $\mathrm{p}=0.001)$. SAl QRST was larger in women with CVD as compared with CVD-free women or men $(+15.1$ (3.8-26.4) mV*ms; $p=0.009)$. Men with CVD had a smaller $\mathrm{T}$ area (by $5.1(95 \% \mathrm{Cl} 1.2$ to 9.0$) \mathrm{mV}^{\star} \mathrm{ms}$ ) and T peak magnitude (by $44(95 \% \mathrm{Cl} 16$ to 71$) \mu \mathrm{V}$ ) than CVD-free men. $T$ vectors pointed more posteriorly in women as compared with men (peak T azimuth + 17.2(8.9-25.6) $p<0.0001$ ), with larger sex differences in $T$ azimuth in some families by $+26.3(7.4-45.3)^{\circ} ; p=0.006$.

Conclusions There are sex differences in the electrical signature of CVD in African-American men and women. There is a significant effect of unmeasured genetic and environmental factors on cardiac repolarisation.
Strengths and limitations of this study

- This large community study of African-American adults is one of few studies with the nested family cohort study, thus offering insight into the effect of unmeasured environmental exposures and genetic variations.

- In this sizeable community-dwelling cohort of African-Americans, more than half of the participants were female, thus strengthening the statistical analyses conducted.

- This ancillary study of the prospective National Institute of Health (NIH)-funded Jackson Heart Study cohort used a well-validated strict definition of prevalent cardiovascular disease and rich phenotyping, thus offering rigorous adjustment for cardiovascular risk factors, socioeconomic and anthropometric characteristics.

- Cross-sectional design precluded the causal interpretation of the observed associations.

- Excluded from the current study the Jackson Heart Study participants with missing covariates were somewhat different from those who were included, thus limiting the generalisability of the study findings.

\section{INTRODUCTION}

Over the decades, African-American men and women carry the highest burden of cardiovascular disease (CVD) among all race/ethnic groups in the USA. ${ }^{1}$ ECG is an inexpensive and widely available tool for cardiovascular assessment.

Sex and race discrimination do exist in modern medicine. Despite the knowledge of the biological sex differences, it is widely accepted to apply findings (norms, thresholds, stratification limits) derived from studies conducted predominantly in men also to women. While racial $^{2}$ and sex differences ${ }^{3}$ in ECG characteristics have been previously acknowledged, sex differences in the 
association of prevalent CVD with ECG phenotype have been studied mostly in white persons.

Global electrical heterogeneity $(\mathrm{GEH})^{4}$ is a novel vectorcardiographic (VCG) phenotype, ${ }^{5}$ based on Wilson's ventricular gradient idea. Ventricular gradient defines the vector along which heterogeneity in excitation and refractoriness is the most prominent. ${ }^{6-8}$ Wilson's frontal plane ventricular gradient was extended into 3-dimensions (the spatial ventricular gradient $(\mathrm{SVG})$ ) in $1954 .^{9}{ }^{10}$ In 1957, Burger published mathematical proof of the SVG's independence of the activation path and the SVG's direction pointing to the myocardium with the shortest duration of the excited state. ${ }^{11}$ We quantify GEH by measuring five SVG vector features (magnitude, direction (azimuth and elevation), a scalar value sum absolute QRST integral (SAI QRST), and spatial QRS-T angle) on orthogonal XYZ ECG. ${ }^{5}{ }^{12}$ GEH is associated with sudden cardiac death (SCD), ${ }^{13}$ cardiovascular mortality, ${ }^{14}$ and left ventricular dysfunc$\operatorname{tion}^{15}$ after rigorous adjustment for known cardiovascular risk factors. Sex differences in GEH have been shown predominantly in white population. ${ }^{3}{ }^{14}$ However, sex differences in GEH and an association of prevalent CVD with GEH in African-American men and women have not been previously studied.

To address this knowledge gap, we conducted a crosssectional study of GEH in African-American participants of the Jackson Heart Study (JHS) to investigate the crosssectional associations of prevalent CVD and sex with GEH. We hypothesised that (1) the prevalent CVD is associated with GEH after adjustment for demographic, anthropometric, socioeconomic and traditional cardiovascular risk factors, (2) there are sex differences in GEH and (3) sex modifies an association of prevalent CVD with GEH.

\section{METHODS}

\section{Study population}

The JHS was initiated in 1998 as a prospective cohort study of CVD in African-Americans. ${ }^{16}{ }^{17}$ The JHS enrolled 5306 participants from the Jackson, Mississippi metropolitan area from 2000 to 2004. Recruitment strategies included: (1) enrolment of the Atherosclerosis Risk in Communities (ARIC) ${ }^{18}$ study participants, (2) random and (3) volunteer recruitment pools and (4) enrolment of secondary family members. Eligible participants were 35-84 years of age, except in a nested family cohort, which included younger participants (21-84 years of age).

In this cross-sectional study, we included JHS participants who had analysable resting 12-lead ECG recorded as a part of the third clinical examination in 2009-2013 (figure 1; $\mathrm{n}=3717$ ). We further excluded participants with missing major risk factor (hypertension and smoking history) and anthropometric data $(\mathrm{n}=38)$, and missing covariates $(\mathrm{n}=768)$. This study population included 3001 participants (figure 1A).

\section{Vectorcardiogram and ECG analysis}

Raw digital ECG signal was analysed in the Tereshchenko laboratory at OHSU, as previously described ${ }^{5121319}$ Briefly, the analysis includes several steps. First, each cardiac beat was manually labelled by at least two physician investigators (KJL, KAP and LGT). Then, 12-lead ECG was transformed into XYZ ECG, using Kors transformation. ${ }^{20}$ Using only one (dominant) type of beat, the time-coherent global median beat was constructed, and the origin of the heart vector was identified. ${ }^{19}$ In this study, we included three categories of median beats. Normal $(\mathrm{N})$ category included normal sinus median beat, atrial paced median beat, junctional median beat and ectopic atrial median beat. The ventricular pacing (VP) category included ventricular paced, and both atrial and ventricular paced median beats. The supraventricular (S) category included median beats of atrial fibrillation or atrial flutter with consistently one type of ventricular conduction.

Spatial peak and spatial area QRS, T and SVG vectors were constructed, and their direction (azimuth and elevation) and magnitudes were measured. ${ }^{512}{ }^{19}$ Scalar values of SVG were measured by SAI QRST ${ }^{21-23}$ and by QT integral on vector magnitude (VM) signal. ${ }^{12}$ Both area and peak QRS-T angles were measured. ${ }^{512} 19$ Quality control of automated ECG analysis was performed by investigators (KTH and NMR) with the aid of visual display. The open-source MATLAB (MathWorks, Natick, Massachusetts, USA) code is provided at https://physionet.org/ physiotools/geh and https://github.com/Tereshchenkolab/Origin.

Traditional ECG measurements were performed by the $12 \mathrm{SL}$ algorithm as implemented in Magellan ECG Research Workstation V2 (GE Marquette Electronics, Milwaukee, Wisconsin, USA) and included median beat measurements (QRS and QT intervals). QT interval was corrected for heart rate by several approaches: Bazett, Fridericia, Hodge and Framingham, as provided by the JHS Coordinating Centre. Cornell voltage was calculated as the sum of the $\mathrm{R}_{\mathrm{avL}}$ and the $\mathrm{S}_{\mathrm{v} 3}$ amplitudes.

Ventricular conduction abnormalities were diagnosed using Minnesota code ${ }^{24}$ at the EPICARE (Wake Forest University, North Carolina, USA). Minnesota code 7-1-1 (left bundle branch block), 7-4 (intraventricular block), 6-8 (pacemaker) and 6-6 (intermittent aberrant ventricular conduction) were included.

\section{Prevalent CVD}

Prevalent CVD was defined during the third clinical examination if at least one of the following was present: (1) history of coronary heart disease (CHD) defined as either self-reported prior myocardial infarction (MI) (diagnosed by a doctor or health professional, or hospitalisation for MI), or ECG diagnosis of MI, (2) history of cardiac procedure defined as either prior coronary revascularisation (coronary artery bypass grafting or percutaneous coronary intervention) or peripheral arterial revascularisation or (3) prior carotid angioplasty or carotid endarterectomy or (4) self-reported stroke history 


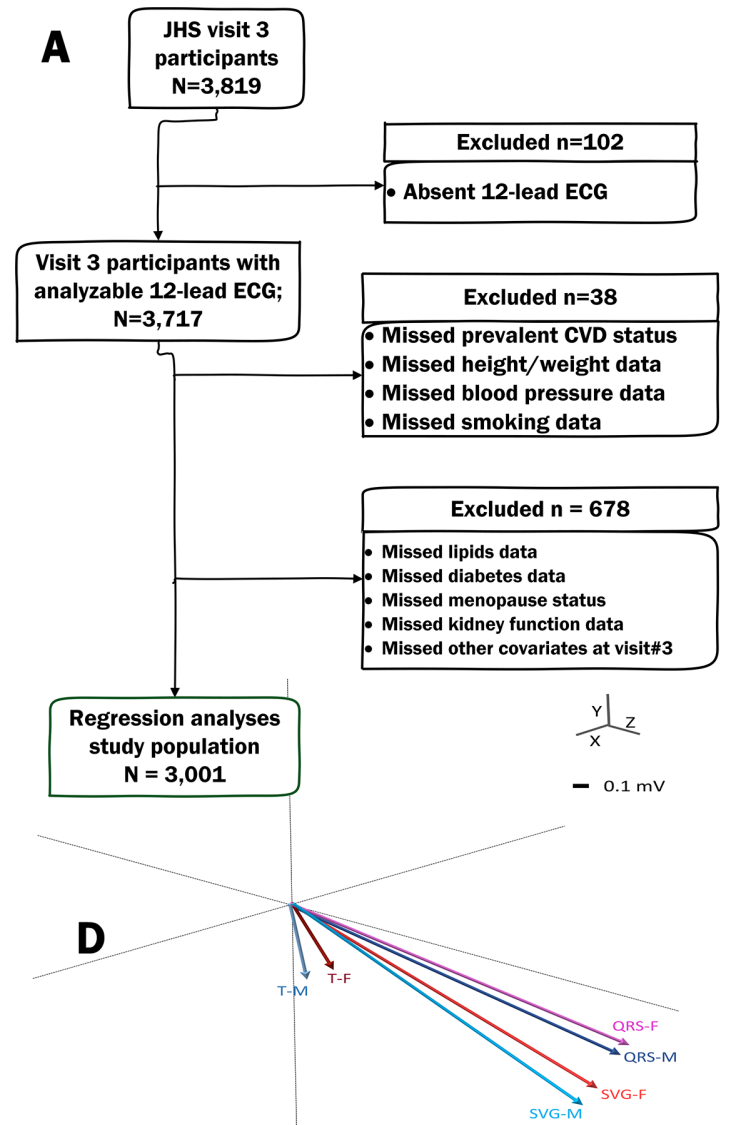

B. Linear Regression analysis

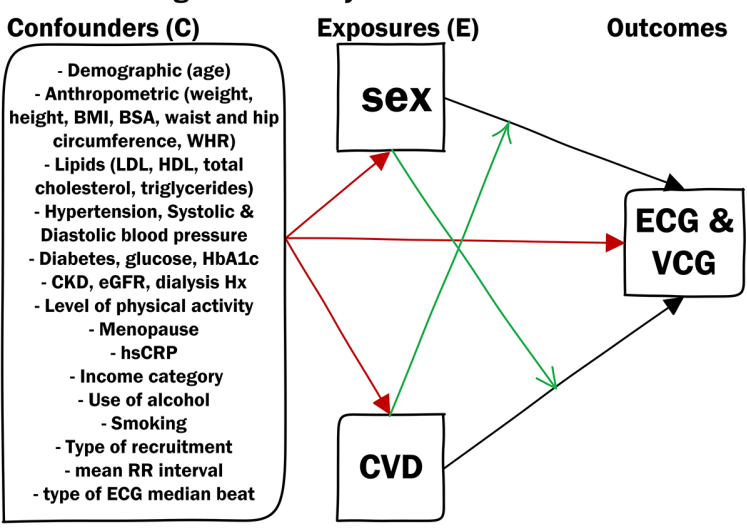

C. Mixed models with random intercept Fixed Effect
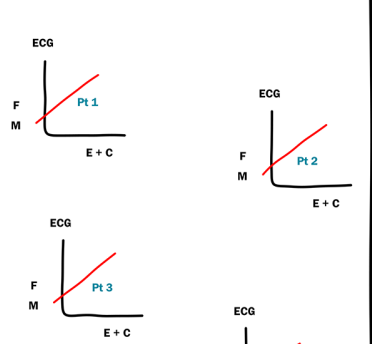
Random Intercept
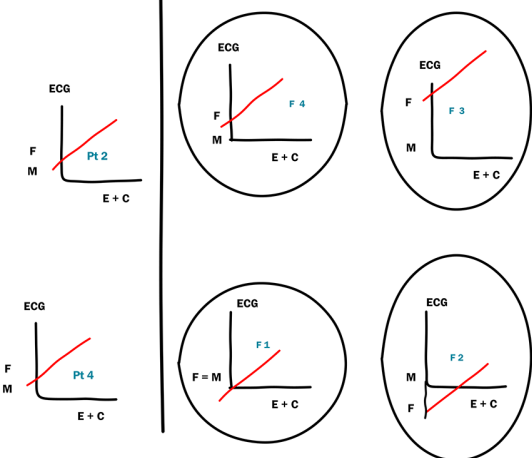

Figure 1 (A) Flow chart of study cohort development. (B) Directed acyclic graph of the regression analysis. Black arrows indicate the studied associations. Green arrows indicate interaction (effect modification). Red arrows connect confounders with exposures and outcomes. (C) Schematic illustration of a linear regression model (or fixed 'within family' effect) and a mixed model with a random intercept (between families effect). (D) Schematic presentation of the average male (blue) and female (red) peak QRS, T, and SVG vectors. SVG, spatial ventricular gradient.

(diagnosed by a doctor or health professional). Stable angina pectoris was not included in the CVD definition.

\section{Covariates: cardiovascular risk factors measured at the third clinical examination}

The third clinical examination included physical examination, anthropometry, a survey of medical history and cardiovascular risk factors and blood and urine collection. Height and weight were measured, and body mass index (BMI) and body surface area (BSA) were calculated. BMI categories included under or normal weight $\left(<25.0 \mathrm{~kg} / \mathrm{m}^{2}\right)$, overweight $\left(25.0\right.$ to $\left.<30.0 \mathrm{~kg} / \mathrm{m}^{2}\right)$ or obese $\left(\geq 30.0 \mathrm{~kg} / \mathrm{m}^{2}\right)$. The dimensionless waist-to-hip ratio (WHR) was calculated as the ratio of the waist's circumference to that of the hips. Self-reported postmenopausal status for women was defined as no menstrual periods during the past 2 years. ${ }^{25}$

Smoking status was defined as current, former and never smoker. The use of alcohol was categorised as yes (in the past 12 months) vs no. Physical activity was characterised according to the American Heart Association classification ${ }^{26}$ as ideal ( $\geq 75 \mathrm{~min}$ of vigorous or $\geq 150 \mathrm{~min}$ of moderate or combined physical activity per week), intermediate $(<75 \mathrm{~min}$ of vigorous or $<150 \mathrm{~min}$ of moderate or combined physical activity per week) or poor (no vigorous or moderate physical activity).

Hypertension was defined as blood pressure $\geq 140 / 90 \mathrm{~mm} \mathrm{Hg}$ or the use of antihypertensive therapy. Fasting plasma glucose and glycosylated haemoglobin (HbAlc) levels were measured as previously described. ${ }^{27}$ Diabetes was defined per 2010 American Diabetes Association guidelines as fasting plasma glucose $\geq 126 \mathrm{mg}$ / $\mathrm{dL}$ or $\mathrm{HbA} 1 \mathrm{c} \geq 6.5 \%$ or use of antidiabetic medications within 2 weeks prior to the clinic visit. Fasting total cholesterol, low-density lipoprotein (LDL), highdensity lipoprotein (HDL) and triglyceride levels were measured. ${ }^{28}$

The estimated glomerular filtration rate $\left(\mathrm{eGFR}_{\mathrm{CKD}-\mathrm{FPI}}\right)$ was calculated using the Chronic Kidney Disease Epidemiology Collaboration equation $\left(\mathrm{mL} / \mathrm{min} / 1.73 \mathrm{~m}^{2}\right)$. Self-reported history of chronic kidney disease (CKD) and dialysis was recorded. Systemic inflammation was assessed by high-sensitivity $\mathrm{C}$ reactive protein (hsCRP), which was measured in serum as previously described. ${ }^{29}$

Family income was categorised as at least US $\$ 75000$ per year vs less than US\$75000 per year. 


\section{Families structure}

Per the design, the JHS enrolled the secondary family members and comprised a Family Cohort that included nearly 300 pedigrees. ${ }^{30}$ In this study, to assess the effect of unmeasured environmental and genetic factors, we comprised family units of participants with the same 4-symbols code indicating similar family names.

\section{Statistical analysis}

Unadjusted comparison

Normally distributed continuous variables were reported as mean $\pm \mathrm{SD}$ and compared using the t-test. Variables with a skewed distribution were reported as the median and IQR and compared using the Wilcoxon rank-sum test. Categorical variables were compared using the $\chi^{2}$ test.

\section{Analysis of circular variables}

Circular variables (azimuth and elevation angles of QRS, $\mathrm{T}$ and SVG vectors, and QRS-T angles) were presented as mean and $95 \%$ CI. Two-sample tests for circular variables included the Watson U-square statistic and the Kuiper statistics.

As distributions of QRS-T angles and SVG elevation angles were normal or nearly normal, and their values were only positive, ranging from $0^{\circ}$ to $180^{\circ}$, we included them in all regression analyses without transformation. As SVG azimuth angles were ranging from $-180^{\circ}$ to $+180^{\circ}$, we transformed SVG azimuth by doubling its value and then adding $360^{\circ} .{ }^{2}{ }^{31}$ For interpretation, we then transformed SVG azimuth back.

\section{Adjusted linear models}

To answer whether sex and prevalent CVD are independently associated with GEH (figure 1B), we constructed linear models with ECG and VCG measurements as outcome variables (one by one) and adjusted for known confounders ${ }^{131521-23} 32$ that were measured during the third clinical examination. All models were adjusted for age, anthropometric characteristics (weight, height, BMI, BSA, waist and hip circumference, WHR), lipid levels (total cholesterol, LDL, HDL, triglycerides), hypertension and levels of systolic and diastolic BP, diabetes and levels of fasting glucose and HbA1c, CKD, history of dialysis, and eGFR ${ }_{\text {CKD-EPI }}$, hs-CRP, levels of physical activity, smoking, use of alcohol, menopausal state and socioeconomic factors (income category). To account for unmeasured confounders, we adjusted for the study recruitment type. All models were also adjusted for the type of median beat (N, S or VP). All models, except the model for heart rate, were adjusted for mean RR' interval. As we previously showed that sex modifies an association of GEH with $\mathrm{SCD},{ }^{3}$ we included an interaction term of sex with prevalent CVD status in all models.

The linear model assumes that the error terms are independent, which may not be the case in our study, as the JHS enrolled families, and the error terms are likely correlated within families. Therefore, we first compared the fit of two models: linear regression and mixed linear model with random intercept (figure 1C). Measuring a random effect is a way of accounting for unmeasured differences between family units. Intercept is a predicted value of outcome if all predictors in the model are equal to zero (at the reference level). We used the likelihood ratio test to compare the fit of linear regression and mixed linear model with random intercept. If a mixed model with random intercept was a better fit, we further used the generalised least squares (GLS) estimator, which does not require normality of the residuals. GLS is a weighted average of between and within effects. We reported both fixed (within families) and random (between families) effects. We used the Hausman specification test to determine whether we should be allowed to use a GLS estimator or if we should use the fixed (within) effect model only. The Hausman specification test describes whether there are systematic differences between the GLS and fixed effect estimators due to the correlation of predictor variable with the error term (omitted variable bias or endogeneity).

Statistical analysis was performed using STATA MP V.16.1 (StataCorp). A $p<0.05$ was considered statistically significant. We used the Strengthening the Reporting of Observational Studies in Epidemiology cross-sectional checklist when writing our report. ${ }^{33}$

\section{Patient and public involvement}

Patients or the public were not involved in the design, conduct or reporting of this study. However, the study participants and the public are involved in the dissemination plans of our research. A lay summary of the manuscript in 500 words was provided to the JHS (https:/ / www. jacksonheartstudy.org/) Publication Committee, which plans community engagement events.

\section{RESULTS \\ Study population}

On average, study participants were 62 years of age; more than half were female (table 1) and were obese. Nearly three-quarters of participants had hypertension, and onethird of the participants were current or former smokers.

There were few differences in participants' characteristics with missing covariates who were excluded from the regression analyses. Excluded participants were more likely to be younger females, with smaller height, lower systolic blood pressure, higher BMI and faster heart rate (online supplemental table 1). Nevertheless, VCG characteristics of included and excluded participants were broadly similar.

\section{Family units structure}

There were 863 family units in our study. Nearly half of them consisted of a single person (343 units; $40 \%$ ), and $17 \%$ (149 units) consisted of two participants. There were 16 large family units (2\%) with 20-79 family members per unit, accounting for $24 \%$ of the study population $(n=713)$. 
Table 1 Comparison of clinical characteristics in men and women

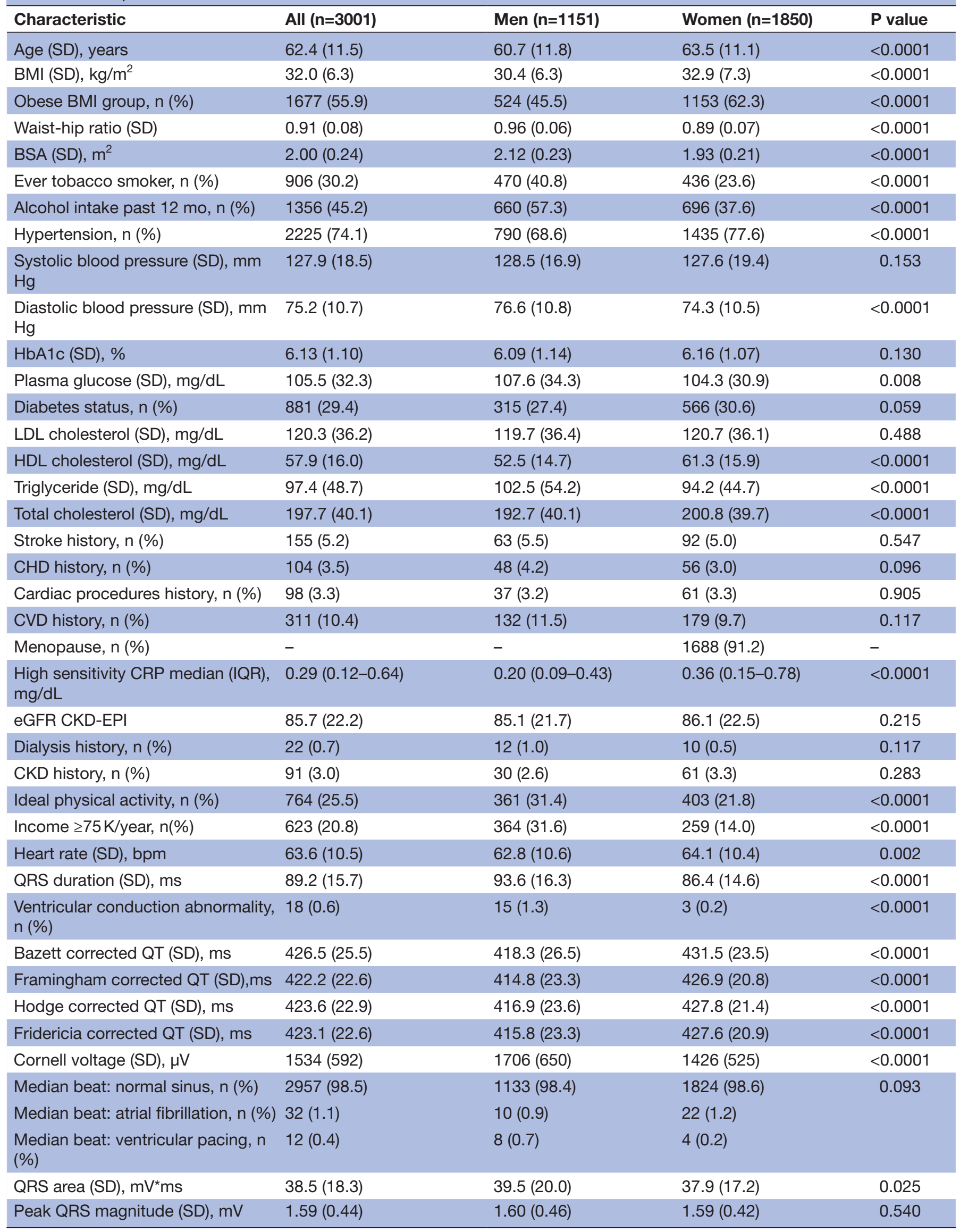




\begin{tabular}{|c|c|c|c|c|}
\hline Characteristic & All $(n=3001)$ & Men $(n=1151)$ & Women $(n=1850)$ & $P$ value \\
\hline Area QRS azimuth $(95 \% \mathrm{Cl}),^{\circ}$ & 20.7 (19.9 to 21.5$)$ & 21.4 (19.8 to 23.0$)$ & 20.3 (19.3 to 21.2$)$ & $<0.001$ \\
\hline Area QRS elevation $(95 \% \mathrm{Cl}){ }^{\circ}$ & 73.8 (73.2 to 74.4$)$ & 75.7 (74.6 to 76.8$)$ & 72.6 (71.8 to 73.3$)$ & $<0.001$ \\
\hline Peak QRS elevation $(95 \% \mathrm{Cl}){ }^{\circ}$ & 72.7 (72.2 to 73.2$)$ & 74.7 (73.8 to 75.5$)$ & 71.5 (70.9 to 72.1$)$ & $<0.001$ \\
\hline Peak T magnitude (SD), mV & $0.36(0.16)$ & $0.40(0.17)$ & $0.33(0.15)$ & $<0.0001$ \\
\hline Area T azimuth $(95 \% \mathrm{Cl}){ }^{\circ}$ & $-45.2(-46.2$ to -44.1$)$ & $-52.3(-53.9$ to -50.7$)$ & $-40.6(-41.9$ to -39.2$)$ & $<0.001$ \\
\hline Peak T azimuth $(95 \% \mathrm{Cl}){ }^{\circ}$ & $-36.3(-37.4$ to -35.1$)$ & $-46.1(-47.8$ to -44.4$)$ & $-30.0(-31.4$ to -28.6$)$ & $<0.001$ \\
\hline Area T elevation $(95 \% \mathrm{Cl}){ }^{\circ}$ & 75.8 (75.3 to 76.3) & 77.7 (76.9 to 78.4$)$ & 74.6 (73.9 to 75.3$)$ & $<0.001$ \\
\hline Area SVG azimuth $(95 \% \mathrm{Cl}){ }^{\circ}$ & $-14.3(-15.1$ to -13.4$)$ & $-22.2(-23.6$ to -20.9$)$ & $-9.4(-10.4$ to -8.5$)$ & $<0.001$ \\
\hline Peak SVG azimuth $(95 \% \mathrm{Cl}){ }^{\circ}$ & $3.4(2.6$ to 4.1$)$ & $0.6(-0.9$ to 2.1$)$ & $5.0(4.2$ to 5.8$)$ & $<0.001$ \\
\hline Area SVG elevation $(95 \% \mathrm{Cl}),^{\circ}$ & 71.8 (71.3 to 72.3$)$ & 74.0 (73.1 to 74.9$)$ & 70.4 (69.8 to 71.1$)$ & $<0.001$ \\
\hline Peak SVG elevation $(95 \% \mathrm{Cl}){ }^{\circ}$ & 71.2 (70.7 to 71.6$)$ & 73.1 (72.3 to 73.9$)$ & $69.9(69.4$ to 70.5$)$ & $<0.001$ \\
\hline SAI QRST (SD), mV*ms & $154.5(51.7)$ & $169.4(55.4)$ & $109.1(46.9)$ & $<0.0001$ \\
\hline VM QT integral (SD), mV*ms & $103.4(34.5)$ & $113.8(36.9)$ & $97.0(31.3)$ & $<0.0001$ \\
\hline Area QRS-T angle $(95 \% \mathrm{Cl}){ }^{\circ}$ & $67.3(66.1$ to 68.6$)$ & 75.0 (72.9 to 77.1$)$ & 62.7 (61.2 to 64.2) & $<0.001$ \\
\hline Peak QRS-T angle $(95 \% \mathrm{Cl}){ }^{\circ}$ & 48.3 (47.1 to 49.6$)$ & 55.7 (53.4 to 57.9 ) & 44.1 (42.7 to 45.5$)$ & $<0.001$ \\
\hline
\end{tabular}

BMI, body mass index; BSA, body surface area; CHD, coronary heart disease; CKD, chronic kidney disease; CKD-EPI, Chronic Kidney Disease Epidemiology Collaboration; CRP, C reactive protein; CVD, cardiovascular disease; eGFR, estimated glomerular filtration rate; HbA1c, glycosylated haemoglobin; HDL, high-density lipoprotein; LDL, low-density lipoprotein; SVG, spatial ventricular gradient; VM, vector magnitude.

For the vast majority of linear models, the linear regression model provided a better fit than the mixed model. Only four mixed models with random intercept demonstrated a better fit than linear regression: models for QRS duration, area and peak T azimuth and area SVG azimuth. Hausman specification test supported the use of the GLS estimator in these four models.

\section{Comparison of men and women}

Female study participants were older, less physically active, with a higher prevalence of obesity and hypertension, higher levels of hsCRP and a lower income than male participants (table 1). On the other hand, women were less likely to smoke and consume alcohol and had a more favourable lipid profile than men. There were no statistically significant differences in the CVD prevalence between men and women (table 1).

In unadjusted comparison (table 1), women had a faster heart rate, more narrow QRS, and longer QTc than men. There were no differences in peak SVG and peak QRS magnitudes between men and women; however, SAI QRST and area SVG, as well as QRS-T angles were smaller in women than in men. There were significant differences in SVG direction: SVG pointed higher up and further anteriorly in men than in women. There were no differences in the type of median beat between men and women; only approximately $1 \%$ of participants had S and VP types of the median beat (table 1 ).

After adjustment for confounders (table 2), the QRS-T angle remained larger in men than in women (figure 2). The SVG vector pointed farther upward and anteriorly in men than in women (figure 2). A significant random effect for area SVG azimuth (figure 3) indicated a range of meaningful differences (up to $40^{\circ}$ ) in SVG azimuth for different families. Differences between families in SVG azimuth were mostly due to differences in $\mathrm{T}$ azimuth. Both area and peak $T$ vectors pointed more posteriorly in women as compared with men (figure 3), and there was a significant random effect (table 2 and figure 3 ), resulting in larger sex differences in $\mathrm{T}$ azimuth in some families. Area SVG, SAI QRST (figure 4), and T area with T VMs (figure 5) and elevation of QRS and T vectors (figure 6) were smaller in women than in men. However, there were no sex differences in peak SVG magnitude and QRS vector azimuth and magnitude (figures 5-6).

\section{GEH in participants with and without prevalent CVD}

Prevalent CVD was diagnosed in 311 out of 3001 participants $(10.4 \%)$. After full adjustment, the QRS-T angle was significantly wider in participants with CVD in both 
Table 2 Difference in GEH in women (as compared with men) and participants with prevalent CVD (as compared with CVDfree)

\begin{tabular}{|c|c|c|c|c|c|c|}
\hline \multirow{2}{*}{$\begin{array}{l}\text { ECG/VCG } \\
\text { characteristic }\end{array}$} & \multicolumn{2}{|l|}{ Women versus men } & \multicolumn{2}{|c|}{ Prevalent CVD versus CVD-free } & \multicolumn{2}{|c|}{$\begin{array}{l}\text { Women with CVD versus men } \\
\text { and CVD-free women }\end{array}$} \\
\hline & Difference $(95 \% \mathrm{Cl})$ & $P$ value & Difference $(95 \% \mathrm{Cl})$ & $P$ value & Difference $(95 \% \mathrm{Cl})$ & $P$ value \\
\hline Heart rate, bpm & $+2.6(0.7$ to 4.5$)$ & 0.007 & $-0.1(-1.8$ to 1.6$)$ & 0.912 & $+0.1(-2.2$ to 2.3$)$ & 0.945 \\
\hline $\begin{array}{l}\text { QRS duration, } \\
\text { ms\#(mixed) }\end{array}$ & $-5.0(-7.8$ to -2.1$)$ & 0.001 & $+3.1(0.5$ to 5.7$)$ & 0.020 & $+1.5(-1.9$ to 4.9$)$ & 0.374 \\
\hline Between effect & $+0.1(-6.5$ to 6.7$)$ & 0.987 & $+2.1(-3.7$ to 7.8$)$ & 0.481 & $+2.6(-4.7$ to 9.9$)$ & 0.490 \\
\hline $\begin{array}{l}\text { Hausman } p=0.979 \\
\text { Within effect }\end{array}$ & $-6.1(-9.3$ to -2.8$)$ & $<0.0001$ & $+3.4(0.4$ to 6.3$)$ & 0.027 & $+1.3(-2.6$ to 5.1$)$ & 0.524 \\
\hline $\begin{array}{l}\text { Bazett corrected QT, } \\
\text { ms }\end{array}$ & +11.4 (7.2 to 15.7$)$ & $<0.0001$ & $+4.8(0.9$ to 8.7$)$ & 0.016 & $-3.4(-8.5$ to 1.6$)$ & 0.182 \\
\hline Cornell voltage, mV & $-0.36(-0.48$ to -0.25$)$ & $<0.0001$ & $-0.03(-0.13$ to 0.08$)$ & 0.629 & $+0.07(-0.06$ to 0.20$)$ & 0.308 \\
\hline QRS area, $\mathrm{mV}^{*} \mathrm{~ms}$ & $-1.1(-4.6$ to 2.4$)$ & 0.548 & $+2.3(-0.9$ to 5.5$)$ & 0.151 & $+1.5(-2.7$ to 5.6$)$ & 0.484 \\
\hline $\begin{array}{l}\text { Peak QRS magnitude, } \\
\mathrm{mV}\end{array}$ & $-0.07(-0.15$ to 0.02$)$ & 0.131 & $+0.04(-0.04$ to 0.11$)$ & 0.373 & $+0.01(-0.09$ to 0.11$)$ & 0.841 \\
\hline Area QRS azimuth, ${ }^{\circ}$ & $+1.9(-3.6$ to 7.4$)$ & 0.505 & $+2.3(-2.7$ to 7.4$)$ & 0.368 & $-0.5(-7.1$ to 6.0$)$ & 0.876 \\
\hline Peak QRS azimuth, ${ }^{\circ}$ & $+1.7(-3.4$ to 6.8$)$ & 0.517 & $+7.6(3.0$ to 12.3$)$ & 0.001 & $-2.0(-8.1$ to 4.0$)$ & 0.513 \\
\hline Area QRS elevation, ${ }^{\circ}$ & $-3.9(-7.3$ to -0.5$)$ & 0.026 & $+0.9(-2.2$ to 4.1$)$ & 0.559 & $+2.0(-2.1$ to 6.1$)$ & 0.336 \\
\hline Peak QRS elevation, ${ }^{\circ}$ & $-3.5(-6.1$ to -0.9$)$ & 0.008 & $+1.6(-0.8$ to 4.0$)$ & 0.186 & $+1.7(-1.4$ to 4.8$)$ & 0.270 \\
\hline $\mathrm{T}$ area, $\mathrm{mV}^{*} \mathrm{~ms}$ & $-15.5(-19.7$ to -11.2$)$ & $<0.0001$ & $-5.1(-9.0$ to -1.2$)$ & 0.011 & $+7.2(2.1$ to 12.3$)$ & 0.005 \\
\hline Peak T magnitude, mV & $-0.08(-0.11$ to -0.05$)$ & $<0.0001$ & $-0.04(-0.07$ to -0.02$)$ & 0.002 & $+0.05(0.02$ to 0.09$)$ & 0.003 \\
\hline $\begin{array}{l}\text { Area T azimuth, }{ }^{\circ} \#(G L S \text {, } \\
\text { RE) }\end{array}$ & +14.5 (7.3 to 21.8) & $<0.0001$ & $+0.1(-6.6$ to 6.8$)$ & 0.975 & $+4.5(-4.5$ to 12.8$)$ & 0.352 \\
\hline Between effect & $+27.5(11.0$ to 44.1$)$ & 0.001 & $-16.5(-30.8$ to -2.12$)$ & 0.024 & $+29.9(11.5$ to 48.2$)$ & 0.001 \\
\hline $\begin{array}{l}\text { Hausman } p=0.204 \\
\text { Within effect }\end{array}$ & +11.4 (3.2 to 19.5$)$ & 0.006 & $+3.7(-3.9$ to 11.2$)$ & 0.344 & $-1.7(-11.5$ to 8.2$)$ & 0.736 \\
\hline $\begin{array}{l}\text { Peak T azimuth, }{ }^{\circ} \#(G L S, \\
\text { RE) }\end{array}$ & +17.2 (8.9 to 25.6$)$ & $<0.0001$ & $-0.2(-7.8$ to 7.5$)$ & 0.963 & $+3.7(-6.2$ to 13.7$)$ & 0.459 \\
\hline Between effect & +26.3 (7.4 to 45.3$)$ & 0.006 & $-14.6(-31.0$ to 1.9$)$ & 0.082 & $+19.7(-1.3$ to 40.6$)$ & 0.066 \\
\hline $\begin{array}{l}\text { Hausman } p=0.650 \\
\text { Within effect }\end{array}$ & +14.7 (5.3 to 24.0$)$ & 0.002 & $+3.8(-4.9$ to 12.5$)$ & 0.396 & $-0.7(-12.1$ to 10.6$)$ & 0.897 \\
\hline Area T elevation, ${ }^{\circ}$ & $-3.5(-6.5$ to -0.4$)$ & 0.025 & $+0.3(-2.5$ to 3.1$)$ & 0.832 & $+1.6(-2.0$ to 5.2$)$ & 0.383 \\
\hline Peak T elevation, ${ }^{\circ}$ & $-5.6(-8.7$ to -2.6$)$ & $<0.0001$ & $-0.1(-2.9$ to 2.8$)$ & 0.969 & $+2.2(-1.5$ to 5.9$)$ & 0.235 \\
\hline Area SVG, $\mathrm{mV}^{*} \mathrm{~ms}$ & $-10.6(-15.9$ to -5.3$)$ & $<0.0001$ & $-7.2(-12.1$ to -2.3$)$ & 0.004 & $+6.8(0.4$ to 13.1$)$ & 0.036 \\
\hline $\begin{array}{l}\text { Peak SVG magnitude, } \\
\mathrm{mV}\end{array}$ & $-0.06(-0.16$ to 0.03$)$ & 0.192 & $-0.06(-0.14$ to 0.03$)$ & 0.215 & $+0.05(-0.7$ to 0.16$)$ & 0.433 \\
\hline $\begin{array}{l}\text { Area SVG } \\
\text { azimuth, }{ }^{\circ} \#(G L S, R E)\end{array}$ & $+16.2(10.5$ to 21.9$)$ & $<0.0001$ & $+1.8(-3.4$ to 7.0$)$ & 0.502 & $+5.5(-1.3$ to 12.2$)$ & 0.113 \\
\hline Between effect & +20.8 (8.2 to 33.5 ) & 0.001 & $-13.1(-24.0$ to -2.1$)$ & 0.020 & $+25.0(11.0$ to 39.1$)$ & $<0.0001$ \\
\hline $\begin{array}{l}\text { Hausman } p=0.073 \\
\text { Within effect }\end{array}$ & $+13.6(7.2$ to 20.0$)$ & $<0.0001$ & $+4.0(-1.9$ to 10.0$)$ & 0.184 & $+1.7(-6.1$ to 9.4$)$ & 0.670 \\
\hline Peak SVG azimuth, ${ }^{\circ}$ & +4.8 (0.001 to 9.6$)$ & 0.0499 & $+8.4(4.0$ to 12.8$)$ & $<0.0001$ & $+2.6(-8.3$ to 3.13$)$ & 0.374 \\
\hline Area SVG elevation, ${ }^{\circ}$ & $-4.5(-7.5$ to -1.4$)$ & 0.004 & $-1.2(-4.0$ to 1.6$)$ & 0.393 & $+3.8(0.1$ to 7.3$)$ & 0.042 \\
\hline Peak SVG elevation, ${ }^{\circ}$ & $-3.6(-6.1$ to -1.2$)$ & 0.004 & $+0.9(-1.3$ to 3.2$)$ & 0.412 & $+2.1(-0.8$ to 5.1$)$ & 0.154 \\
\hline SAI QRST, $\mathrm{mV}^{*} \mathrm{~ms}$ & $-29.8(-39.3$ to -20.3$)$ & $<0.0001$ & $-4.3(-123.0$ to 4.5$)$ & 0.338 & +15.1 (3.8 to 26.4$)$ & 0.009 \\
\hline VM QT integral, $\mathrm{mV}^{*} \mathrm{~ms}$ & $-19.7(-26.1$ to -13.4$)$ & $<0.0001$ & $-2.3(-8.2$ to 3.4$)$ & 0.422 & $+10.2(2.6$ to 17.7$)$ & 0.008 \\
\hline Area QRS-T angle, ${ }^{\circ}$ & $-10.7(-17.3$ to -4.1$)$ & 0.001 & $+12.5(6.5$ to 18.5$)$ & $<0.0001$ & $-1.6(-9.4$ to 6.3$)$ & 0.694 \\
\hline Peak QRS-T angle, ${ }^{\circ}$ & $-12.2(-19.4$ to -5.1$)$ & 0.001 & $+15.3(8.7$ to 21.9$)$ & $<0.0001$ & $-1.0(-9.6$ to 7.5$)$ & 0.811 \\
\hline
\end{tabular}

Bold values are statistically significant; $\mathrm{P}<0.05$

CVD, cardiovascular disease; GEH, global electrical heterogeneity; SVG, spatial ventricular gradient; VCG, vectorcardiographic; VM, vector magnitude. 

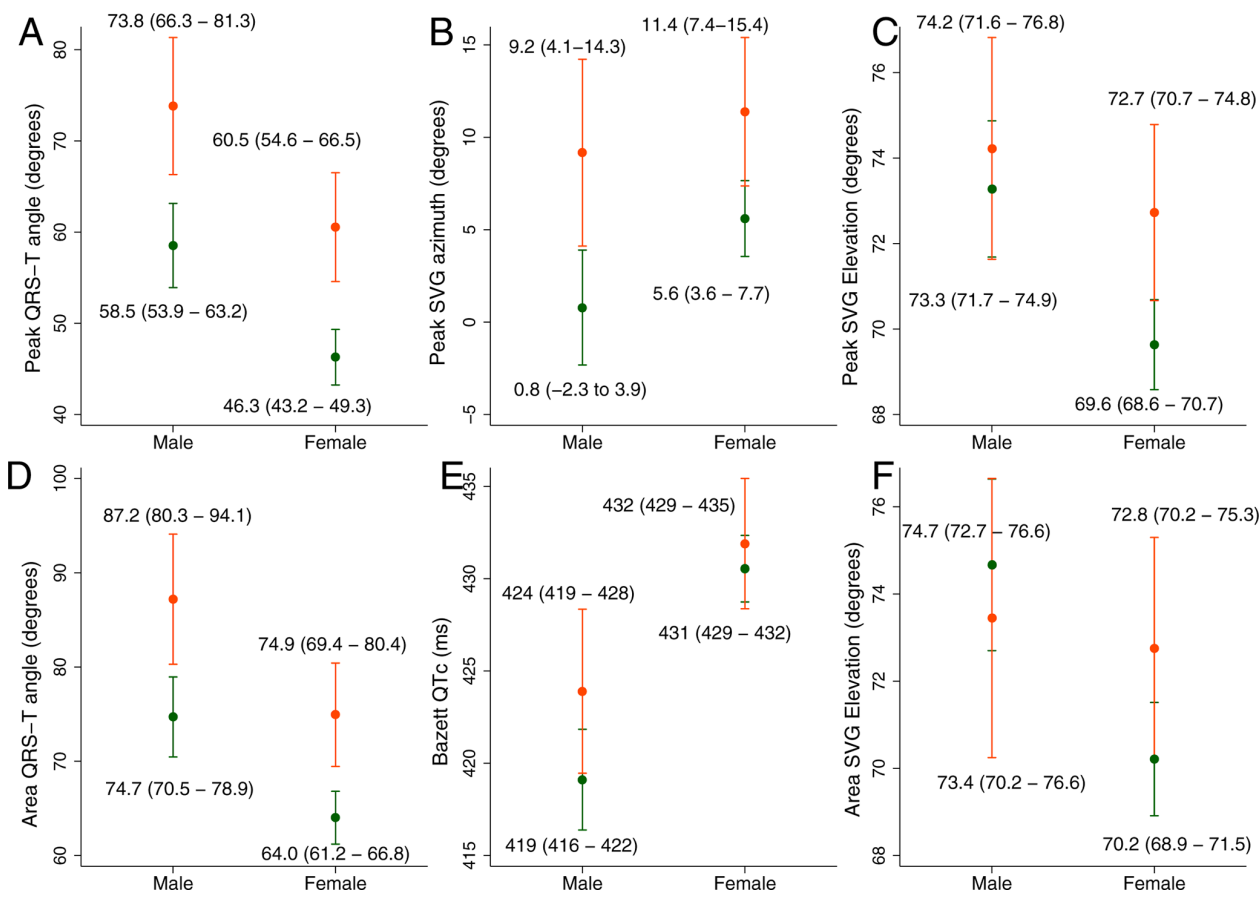

Figure 2 Estimated adjusted marginal (least squares) means and 95\% Cl of (A) peak QRS-T angle, (B) peak SVG azimuth, (C) peak SVG elevation, (D) area QRS-T angle, (E) QTc, (F) area SVG elevation in male and female participants with (orange) and without (green) prevalent CVD. All models were adjusted for age, weight, height, BMI, BSA, waist and hip circumference, WHR, total cholesterol, LDL, HDL, triglycerides, hypertension, levels of systolic and diastolic BP, diabetes, levels of fasting glucose and $\mathrm{HbA1c}, \mathrm{CKD}$, history of dialysis, eGFR $\mathrm{CKD}_{\mathrm{EP} \mid}$, levels of physical activity, smoking, use of alcohol, menopausal state, income, study recruitment, type of median beat and mean RR' interval. BMI, body mass index; BSA, body surface area; CKD, chronic kidney disease; CVD, cardiovascular disease; eGFR, estimated glomerular filtration rate; HbA1c, glycosylated haemoglobin; HDL, high-density lipoprotein; LDL, low-density lipoprotein; SVG, spatial ventricular gradient; WHR, waist-to-hip ratio.
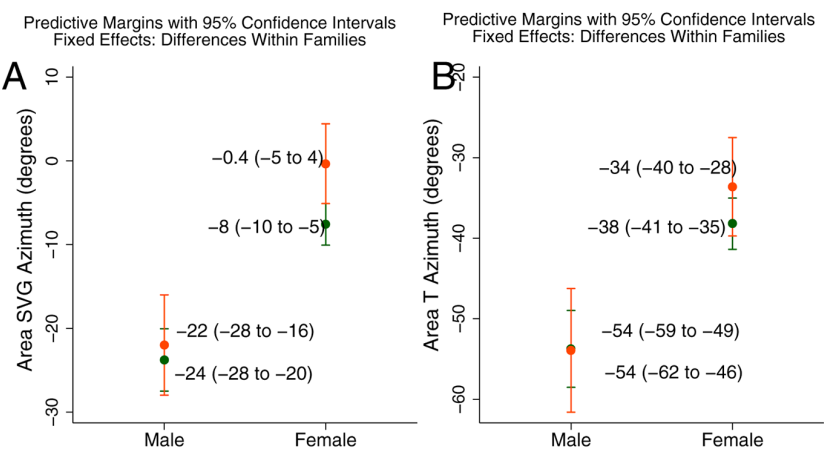

Predictive Margins with 95\% Confidence Intervals
Fixed Effects: Differences Within Families
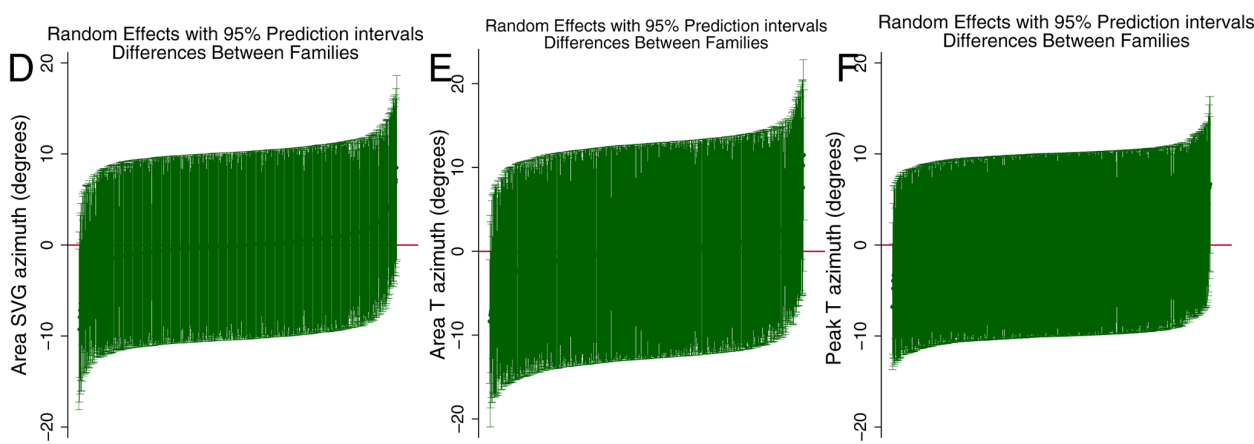

Figure 3 Estimated adjusted (model as described in figure 2 legend) marginal means and $95 \%$ prediction intervals of (A, D) area SVG azimuth, $(B, E)$ area T azimuth and $(C, F)$ peak T azimuth. $(A-C) A$ fixed portion of a linear prediction (within families effect) in male and female participants with (orange) and without (green) prevalent CVD. (D-F) Random intercepts by family (between families effect). CVD, cardiovascular disease; SVG, spatial ventricular gradient. 

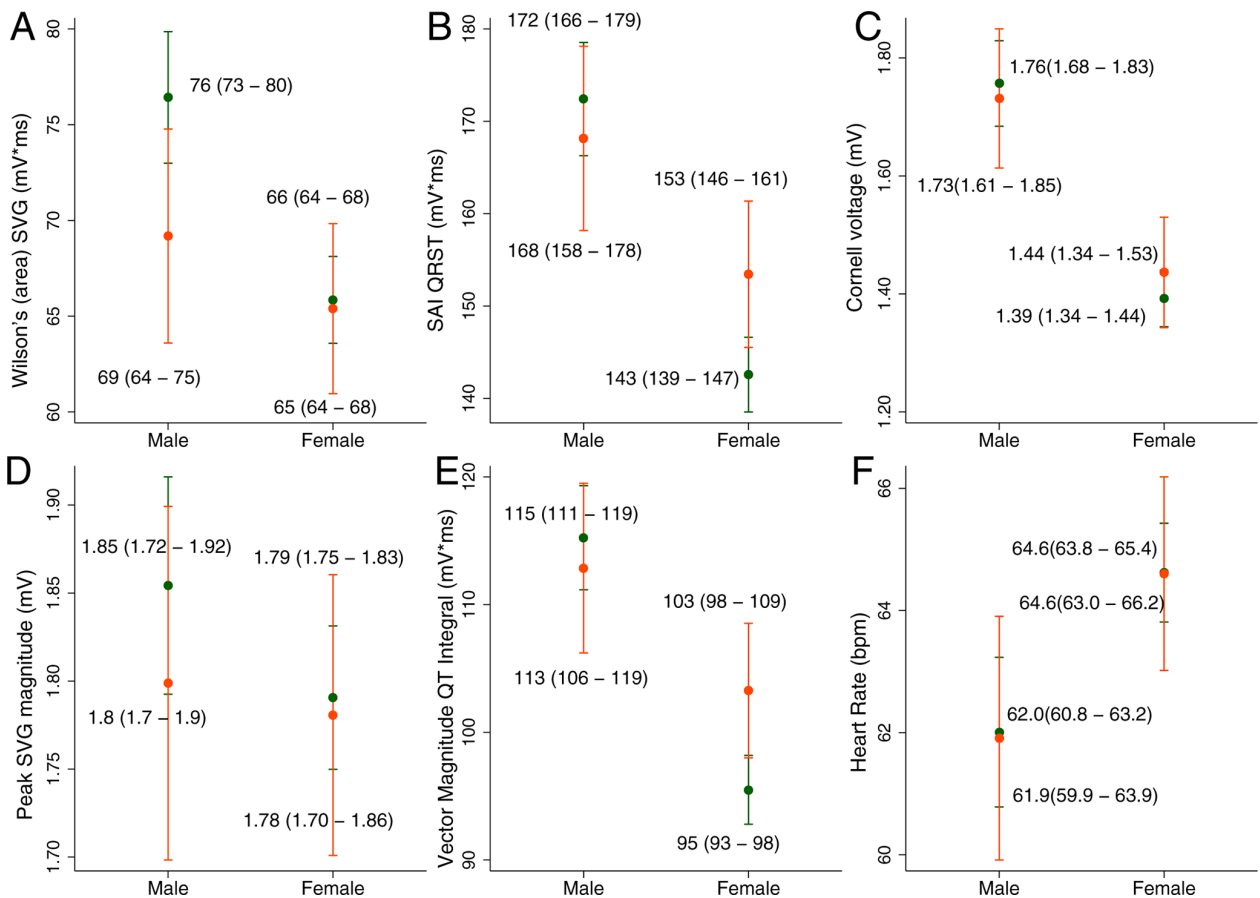

Figure 4 Estimated adjusted (model as described in figure 2 legend) marginal (least squares) means and $95 \% \mathrm{Cl}$ of $(\mathrm{A})$ area SVG, (B) SAI QRST, (C) Cornell voltage, (D) peak SVG magnitude, (E) vector magnitude QT integral, (F) heart rate in male and female participants with (orange) and without (green) prevalent CVD. CVD, cardiovascular disease; SVG, spatial ventricular gradient.

men and women (figure 2). We observed significant effect modification by sex for several GEH characteristics (table 2). Women with CVD had larger SAI QRST (by 10.9 (95\% CI 3.4 to 18.3$) \mathrm{mV}^{*} \mathrm{~ms}$ ) and VM QT integral (by 7.8 (95\% CI 2.8 to 12.7$) \mathrm{mV}^{*} \mathrm{~ms}$ ) than CVD-free women, but there were no differences in men (figure 4). Men with CVD had smaller area SVG (by 7.2 (95\% CI 2.3 to 12.1) $\mathrm{mV}^{*} \mathrm{~ms}$ ), T area (by 5.1 (95\% CI 1.2 to 9.0$) \mathrm{mV}^{*} \mathrm{~ms}$ ), and T peak magnitude (by 44 (95\% CI 16 to 71$) \mu V$ ) than CVD-free men, whereas no differences by CVD status were
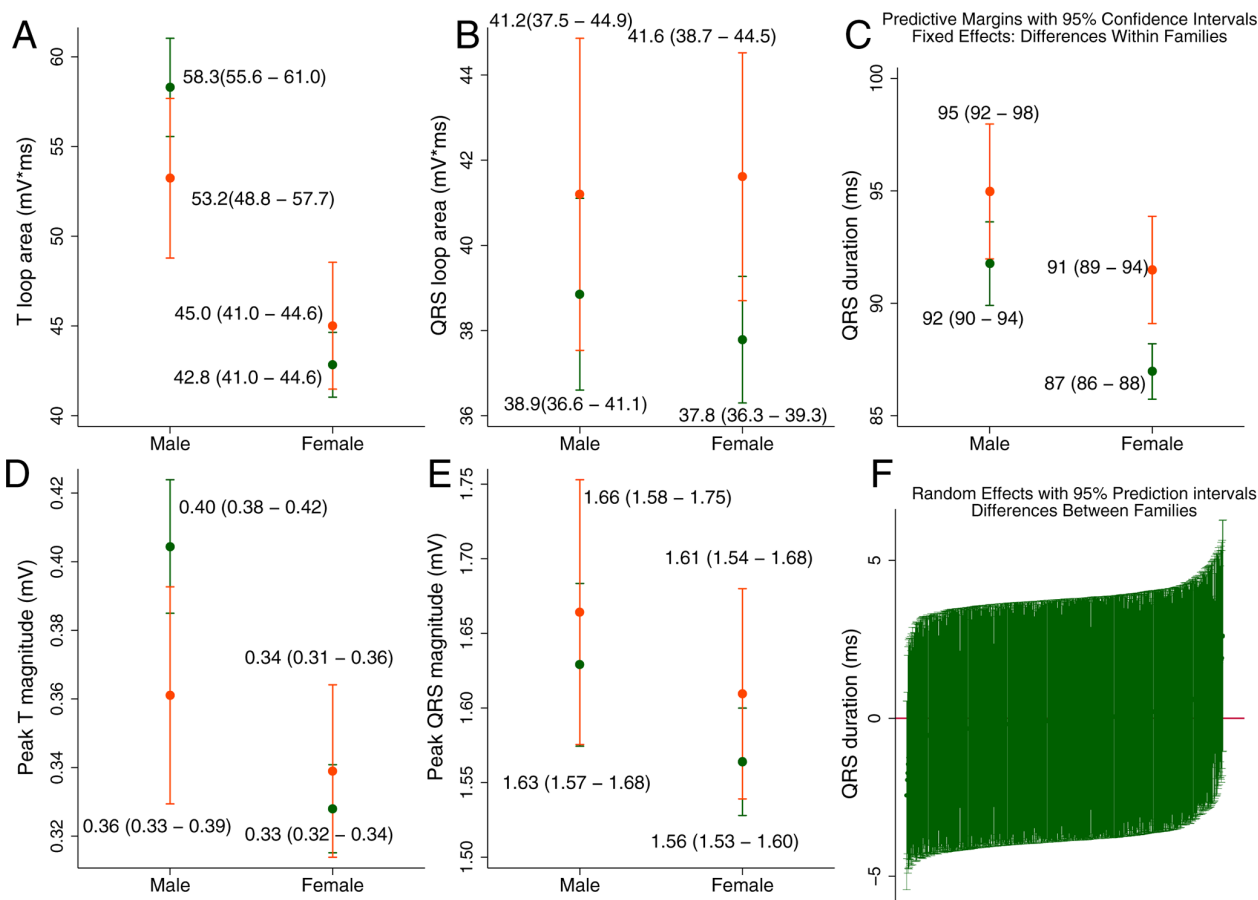

Figure 5 Estimated adjusted (model as described in figure 2 legend) marginal means and 95\% prediction intervals of (A) T area, (B) QRS area, (C, F) QRS duration, (D) peak T\% magnitude, (E) peak QRS magnitude. (A-E) A fixed portion of a linear prediction (within families effect) in male and female participants with (orange) and without (green) prevalent CVD. (F) Random intercepts by family (between families effect). CVD, cardiovascular disease. 

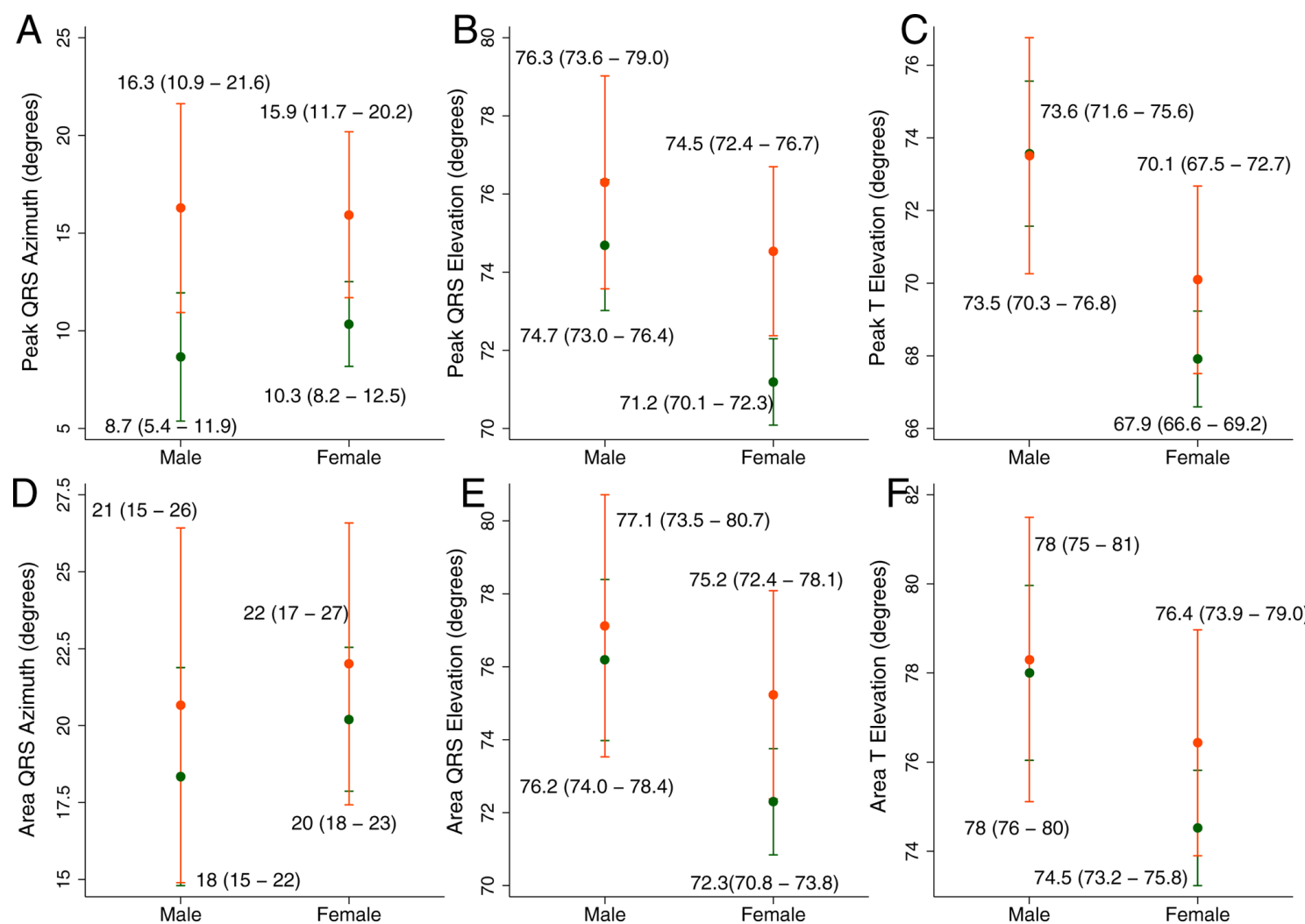

Figure 6 Estimated adjusted (model as described in figure 2 legend) marginal (least squares) means and $95 \% \mathrm{Cl}$ of $(\mathrm{A})$ peak QRS azimuth, (B) peak QRS elevation, (C) peak T elevation, (D) area QRS azimuth, (E) area QRS elevation, (F) area T elevation in male and female participants with (orange) and without (green) prevalent CVD. CVD, cardiovascular disease.

observed in women (figures 4-5). In women with CVD, the SVG vector pointed more superiorly (area SVG elevation larger by $\left.2.5(95 \% \text { CI } 0.2 \text { to } 4.9)^{\circ}\right)$, as compared with CVD-free women (figure 2). However, there was no difference in SVG elevation in men with and without CVD.

\section{DISCUSSION}

This large community-based cross-sectional study of nearly 4000 African-American men and women revealed several novel findings. First, we demonstrated sex differences in VCG after rigorous adjustment for prevalent CVD, cardiovascular risk factors, sociodemographic and anthropometric characteristics. Second, we showed that sex modified an association of CVD with ECG and VCG phenotype. Third, we observed a significant effect of unmeasured genetic and environmental factors on $\mathrm{T}$ and SVG azimuth. The azimuth of T and SVG vectors can serve as sensitive markers of cardiac repolarisation.

\section{Sex differences in GEH}

Consistently with the recent study in the ARIC cohort, ${ }^{3}$ we observed significant sex differences in the SAI QRST and the SVG vector direction, but not in peak SVG magnitude. Importantly, the size of sex differences previously seen in the predominantly white populations ${ }^{312}{ }^{21}$ was mainly similar to that found in African-American men and women in this study. Sex is biologically determined, and sex differences in GEH manifest independently of race. $^{2}$ In this study, we showed sex differences in GEH that persisted after adjustment for anthropometric characteristics, prevalent CVD, and cardiovascular risk factors, suggesting that GEH can detect sex differences in the underlying expression of potassium channels. ${ }^{34}{ }^{35}$ Consistently with our findings, recent analysis of the doubleblind placebo-controlled trial showed that dofetilide had a larger effect on the spatial QRS-T angle in women than in men. ${ }^{36}$

\section{Sex modifies an association of CVD with ECG and VCG phenotype}

Our study corroborated a well-known association of GEH with CVD. ${ }^{22} 233237$ However, little was known about how sex modifies an association of GEH with CVD. In a prospective cohort study conducted in the predominantly white Finnish population, SAI QRST was strongly associated with cardiovascular mortality in women but not in men. ${ }^{14}$ In accordance with Lipponen $e t a l^{14}$ our cross-sectional study observed differences in SAI QRST by CVD status in women but not in men. In ARIC, the spatial QRS-T angle was more strongly associated with fatal CHD in women than in men. ${ }^{38}$ In contrast, sex did not modify an association of QRS-T angle with prevalent CVD in this study, which can be explained by differences in the design and outcome definitions between studies.

In the previous biracial ARIC population study, a substantial number of ECG markers (QRS duration, 
Cornell voltage, SAI QRST, SVG magnitude, heart rate and QTc) were associated with a larger risk of sudden cardiac death (SCD) in women than in men. ${ }^{3}$ Notably, in this cross-sectional study, we newly observed smaller area SVG, T area and T peak magnitude in men with CVD as compared with CVD-free men, but no differences in women. Altogether, our study showed that sex significantly modifies an association of prevalent CVD with GEH.

\section{An effect of unmeasured genetic and environmental factors on repolarisation}

For the first time, our study showed significant random effects carried by family units, manifested by a substantial range of differences in T and SVG azimuth between families. Some family units had very large differences (up to $40^{\circ}$ ) in $\mathrm{T}$ vector direction between family members with different characteristics (eg, male vs female; with vs without CVD). In contrast, other family units either had very little differences in $T$ vector direction between family members with different characteristics, or had opposing differences. This study cannot answer whether observed differences were due to underlying genetic variations or different environmental exposures. Numerous pharmacological, dietary, ${ }^{3940}$ and environmental factors can block the cardiac human ether-à-go-go-related gene channel, ${ }^{41} 42$ which can explain differences in repolarisation characteristics between families. On the other hand, a previous JHS study ${ }^{43}$ showed a common genetic variant SCN5A-1103Y was associated with prolongation of the QT interval and shortening of QRS. In the JHS, $15 \%$ of African-American participants are carriers of $S C N 5 A-1103 Y{ }^{43}$ Intriguingly, a mixed model with random intercept was the optimal fit for QRS duration in this study, suggesting the importance of between-families differences in QRS. Further studies of the effects of environmental exposures and genetic variations on $\mathrm{GEH}^{44}$ are needed.

\section{CONCLUSIONS AND CLINICAL IMPLICATIONS}

In summary, in this study, we showed that the prevalent CVD is associated with GEH after adjustment for demographic, anthropometric, socioeconomic and traditional cardiovascular risk factors and sex modifies an association of prevalent CVD with GEH. Our study provided new evidence of sex differences in the electrical signature of CVD, reflecting unique underlying biological pathways in African-American men and women with and without CVD. VCG and GEH characteristics added multidimensionality in the description of the sex differences. When compared with men, women's SVG points farther posteriorly and more downward. Women with CVD have larger SAI QRST than CVD-free women. In contrast, men with CVD have a smaller T-area than CVD-free men. Importantly, we described a range of differences in the cardiac repolarisation vector's direction in response to unmeasured environmental exposures and genetic variations. Observed sex differences support sex-specific approaches to CVD prediction, prevention and management in African-American men and women.

\section{Author affiliations}

${ }^{1}$ University of Mississippi Medical Center, Jackson, Mississippi, USA

${ }^{2}$ Department of Medicine, Cardiovascular Division, Oregon Health \& Science University School of Medicine, Portland, Oregon, USA

${ }^{3}$ Epidemiological Cardiology Research Center, Division of Public Health Sciences and Department of Medicine, Cardiology Section, Wake Forest School of Medicine, Winston-Salem, North Carolina, USA

${ }^{4}$ Department of Medicine, Cardiovascular Division, The Johns Hopkins University School of Medicine, Baltimore, Maryland, USA

\section{Twitter Larisa G Tereshchenko @Tereshchenkolab}

Acknowledgements The authors thank the staff and participants of the JHS. We thank Francis Phan, MD, and John Johnson, BS, for their help with ECG analyses.

Contributors JDP and KTH equally contributed to the study design and conduct, interpretation of findings and drafting of the manuscript. KTH participated in automated ECG analysis software development, conducted automated ECG analysis and participated in figures preparation. JDP, JM and SM were involved in the JHS design and conduct, and data collection. ES was involved in the JHS ECG data collection and analysis. KL, NR, KAP and LT conducted ECG labelling. NR performed quality control of ECG analyses. All authors interpreted the study findings and revised the manuscript. JACL designed the study and critically revised the manuscript. LT designed the study, handled the study funding, directed the study implementation, including quality assurance and control, conducted statistical analyses and critically revised the manuscript. All authors approved the submitted version and have agreed both to be personally accountable for the author's own contributions and the accuracy and integrity of any part of the work.

Funding The Jackson Heart Study (JHS) is supported and conducted in collaboration with Jackson State University (HHSN268201800013l), Tougaloo College (HHSN268201800014I), the Mississippi State Department of Health (HHSN268201800015I) and the University of Mississippi Medical Centre (HHSN268201800010I, HHSN268201800011I and HHSN268201800012I) contracts from the National Heart, Lung and Blood Institute (NHLBI) and the National Institute for Minority Health and Health Disparities (NIMHD). This work was supported by HL118277 (LT).

Disclaimer The views expressed in this manuscript are those of the authors and do not necessarily represent the views of the National Heart, Lung, and Blood Institute; the National Institutes of Health; or the U.S. Department of Health and Human Services.

Competing interests None declared.

Patient consent for publication Not required.

Ethics approval All study participants provided written informed consent before entering the JHS study. This study was approved by the Oregon Health and Science University Institutional Review Board. All procedures performed in studies involving human participants were in accordance with the ethical standards of the Institutional Review Board and the 1964 Declaration of Helsinki and its later amendments or comparable ethical standards.

Provenance and peer review Not commissioned; externally peer reviewed.

Data availability statement Data are available in a public, open access repository. The Jackson Heart Study data are available through the National Heart, Lung, and Blood Institute's Biological Specimen and Data Repository Information Coordinating Center (BioLINCC) and the National Center of Biotechnology Information's database of Genotypes and Phenotypes (dbGaP). The open-source MATLAB (MathWorks, Natick, Massachusetts, USA) code for ECG analysis is provided at https://physionet. org/physiotools/geh and https://github.com/Tereshchenkolab/Origin. Statistical analysis code is provided at https://github.com/Tereshchenkolab/statistics.

Supplemental material This content has been supplied by the author(s). It has not been vetted by BMJ Publishing Group Limited (BMJ) and may not have been peer-reviewed. Any opinions or recommendations discussed are solely those of the author(s) and are not endorsed by BMJ. BMJ disclaims all liability and responsibility arising from any reliance placed on the content. Where the content includes any translated material, BMJ does not warrant the accuracy and reliability of the translations (including but not limited to local regulations, clinical guidelines, 
terminology, drug names and drug dosages), and is not responsible for any error and/or omissions arising from translation and adaptation or otherwise.

Open access This is an open access article distributed in accordance with the Creative Commons Attribution Non Commercial (CC BY-NC 4.0) license, which permits others to distribute, remix, adapt, build upon this work non-commercially, and license their derivative works on different terms, provided the original work is properly cited, appropriate credit is given, any changes made indicated, and the use is non-commercial. See: http://creativecommons.org/licenses/by-nc/4.0/.

\section{ORCID iD}

Larisa G Tereshchenko http://orcid.org/0000-0002-6976-1313

\section{REFERENCES}

1 Benjamin EJ, Muntner P, Alonso A, et al. Heart disease and stroke Statistics-2019 update: a report from the American heart association. Circulation 2019;139:e56-28.

2 Jensen K, Howell SJ, Phan F, et al. Bringing critical race praxis into the study of electrophysiological substrate of sudden cardiac death: the ARIC study. J Am Heart Assoc 2020;9:e015012.

3 Howell SJ, German D, Bender A, et al. Does sex modify an association of electrophysiological substrate with sudden cardiac death? the Atherosclerosis risk in communities (ARIC) study. Cardiovasc Digit Health J 2020;1:80-8.

4 Waks JW, Tereshchenko LG. Global electrical heterogeneity: a review of the spatial ventricular gradient. J Electrocardiol 2016;49:824-30.

5 Perez-Alday EA, Bender A, German D, et al. Dynamic predictive accuracy of electrocardiographic biomarkers of sudden cardiac death within a survival framework: the Atherosclerosis risk in communities (ARIC) study. BMC Cardiovasc Disord 2019;19:255.

6 Wilson FN, Macleod AG, Barker PS, et al. The determination and the significance of the areas of the ventricular deflections of the electrocardiogram. Am Heart J 1934;10:46-61.

7 Burch GE, Winsor T. A primer of electrocardiography. Philadelphia: Lea \& Febiger, 1945.

8 Mozos I, Hancu M, Cristescu A. Multipolar maps in patients with postinfarction heart failure. J Electrocardiol 2011;44:152-6.

9 Burch GE, Abildskov AA, Cronvich JA. A study of the spatial vectorcardiogram of the ventricular gradient. Circulation 1954:9:267-75.

10 Simonson E, Schmitt OH, Dahl J, et al. The theoretical and experimental bases of the frontal plane ventricular gradient and its spatial counterpart. Am Heart J 1954;47:122-53.

11 Burger HC. A theoretical elucidation of the notion ventricular gradient. Am Heart J 1957;53:240-6.

12 Thomas JA, A Perez-Alday E, Junell A, et al. Vectorcardiogram in athletes: the sun Valley Ski study. Ann Noninvasive Electrocardiol 2019;24:e12614.

13 Waks JW, Sitlani CM, Soliman EZ, et al. Global electric heterogeneity risk score for prediction of sudden cardiac death in the general population: the Atherosclerosis risk in communities (ARIC) and cardiovascular health (CHS) studies. Circulation 2016;133:2222-34.

14 Lipponen JA, Kurl S, Laukkanen JA. Global electrical heterogeneity as a predictor of cardiovascular mortality in men and women. Europace 2018;20:1841-8.

15 Biering-Sørensen T, Kabir M, Waks JW, et al. Global ECG measures and cardiac structure and function: the ARIC study (atherosclerosis risk in communities). Circ Arrhythm Electrophysiol 2018;11:e005961.

16 Wyatt SB, Diekelmann N, Henderson F, et al. A community-driven model of research participation: the Jackson heart study participant recruitment and retention study. Ethn Dis 2003;13:438-55.

17 Taylor HA. Establishing a foundation for cardiovascular disease research in an African-American community--the Jackson Heart Study. Ethn Dis 2003;13:411-3.

18 The Atherosclerosis risk in communities (ARIC) study: design and objectives. The ARIC Investigators. Am J Epidemiol 1989;129:687-702.

19 Perez-Alday EA, Li-Pershing Y, Bender A, et al. Importance of the heart vector origin point definition for an ECG analysis: the Atherosclerosis risk in communities (ARIC) study. Comput Biol Med 2019;104:127-38.

20 Kors JA, van Herpen G, Sittig AC, et al. Reconstruction of the Frank vectorcardiogram from standard electrocardiographic leads: diagnostic comparison of different methods. Eur Heart $J$ 1990;11:1083-92.
21 Sur S, Han L, Tereshchenko LG. Comparison of sum absolute QRST integral, and temporal variability in depolarization and repolarization, measured by dynamic vectorcardiography approach, in healthy men and women. PLoS One 2013;8:e57175.

22 Tereshchenko LG, Cheng A, Fetics BJ, et al. A new electrocardiogram marker to identify patients at low risk for ventricular tachyarrhythmias: sum magnitude of the absolute QRST integral. J Electrocardiol 2011;44:208-16.

23 Tereshchenko LG, Cheng A, Fetics BJ, et al. Ventricular arrhythmia is predicted by sum absolute QRST integralbut not by QRS width. $J$ Electrocardiol 2010;43:548-52.

24 ed.Prineas RJ, Crow RS, Zhang Z-M. The Minnesota code manual of electrocardiographic findings : standards and procedures for measurement and classification. 2nd edn. London: Springer, 2010.

25 Campbell Jenkins BW, Addison C, Wilson G, et al. Association of the joint effect of menopause and hormone replacement therapy and cancer in African American women: the Jackson heart study. Int $J$ Environ Res Public Health 2011;8:2491-504.

26 Bell EJ, Lutsey PL, Windham BG, et al. Physical activity and cardiovascular disease in African Americans in atherosclerosis risk in communities. Med Sci Sports Exerc 2013;45:901-7.

27 Joseph JJ, Echouffo-Tcheugui JB, Kalyani RR, et al. Aldosterone, renin, and diabetes mellitus in African Americans: the Jackson heart study. J Clin Endocrinol Metab 2016;101:1770-8.

28 Carpenter MA, Crow R, Steffes M, et al. Laboratory, reading center, and coordinating center data management methods in the Jackson heart study. Am J Med Sci 2004;328:131-44.

29 Effoe VS, Correa A, Chen H, et al. High-Sensitivity C-reactive protein is associated with incident type 2 diabetes among African Americans: the Jackson heart study. Diabetes Care 2015;38:1694-700.

30 Benjamin I, Brown N, Burke G, et al. American heart association cardiovascular Genome-Phenome study: foundational basis and program. Circulation 2015;131:100-12.

31 Cox NJ. Speaking Stata: in praise of Trigonometric predictors. Stata J 2006;6:561-79.

32 Tereshchenko LG, McNitt S, Han L, et al. ECG marker of adverse electrical remodeling post-myocardial infarction predicts outcomes in MADIT II study. PLoS One 2012;7:e51812.

33 von Elm E, Altman DG, Egger M, et al. The strengthening the reporting of observational studies in epidemiology (STROBE) statement: guidelines for reporting observational studies. Ann Intern Med 2007;147:573-7.

34 Gaborit N, Varro A, Le Bouter S, et al. Gender-related differences in ion-channel and transporter subunit expression in non-diseased human hearts. J Mol Cell Cardiol 2010;49:639-46.

35 Tadros R, Ton A-T, Fiset C, et al. Sex differences in cardiac electrophysiology and clinical arrhythmias: epidemiology, therapeutics, and mechanisms. Can J Cardiol 2014;30:783-92.

36 Stabenau HF, Shen C, Tereshchenko LG, et al. Changes in global electrical heterogeneity associated with dofetilide, quinidine, ranolazine, and verapamil. Heart Rhythm 2020;17:460-7.

37 Oehler A, Feldman T, Henrikson CA, et al. QRS-T angle: a review. Ann Noninvasive Electrocardiol 2014;19:534-42.

38 Zhang Z-M, Rautaharju PM, Prineas RJ, et al. A wide QRS/T angle in bundle branch blocks is associated with increased risk for coronary heart disease and all-cause mortality in the Atherosclerosis risk in communities (ARIC) study. J Electrocardiol 2015;48:672-7.

39 Scholz EP, Zitron E, Kiesecker C, et al. Inhibition of cardiac HERG channels by grapefruit flavonoid naringenin: implications for the influence of dietary compounds on cardiac repolarisation. Naunyn Schmiedebergs Arch Pharmacol 2005;371:516-25.

40 Zitron E, Scholz E, Owen RW, et al. QTc prolongation by grapefruit juice and its potential pharmacological basis: HERG channel blockade by flavonoids. Circulation 2005;111:835-8.

41 Vandenberg JI, Perry MD, Perrin MJ, et al. hERG K(+) channels: structure, function, and clinical significance. Physiol Rev 2012;92:1393-478.

42 Kratz JM, Grienke U, Scheel O, et al. Natural products modulating the hERG channel: heartaches and hope. Nat Prod Rep 2017;34:957-80.

43 Akylbekova EL, Payne JP, Newton-Cheh C, et al. Gene-Environment interaction between SCN5A-1103Y and hypokalemia influences QT interval prolongation in African Americans: the Jackson heart study. Am Heart J 2014;167:116-22.

44 Tereshchenko LG, Sotoodehnia N, Sitlani CM, et al. Genome-Wide associations of global electrical heterogeneity ECG phenotype: the ARIC (atherosclerosis risk in communities) study and $\mathrm{CHS}$ (cardiovascular health study). J Am Heart Assoc 2018;7:e008160. 